\title{
VERIFICATION OF DIRECT MARKETING METHODS UTILIZING BRAIN IMAGING
}

\author{
Toshiyuki OCHIAI' ${ }^{1)}$, Mitsuru SUGANUMA ${ }^{1)}$, Yūichi NAKAMURA ${ }^{1)}$, \\ Akiko SAKAKI'), and Masafumi NAKAGAWA ${ }^{2)}$ \\ ${ }^{1)}$ TOPPAN FORMS CO., LTD. * \\ ${ }^{2}$ School of Medicine, International University Health and Welfare, Japan
}

\begin{abstract}
Using a full-head-scale 48ch near-infrared spectroscopy (NIRS) machine (a system used to visualize brain function), we evaluated brain imaging reactions with regard to four items that are often discussed in the context of direct mail marketing services, namely the difference between paper and electronic media, the difference between a one-time and multiple presentations, the presence or absence of a byname, and the relative number of products being presented.

For the presentation of a small number of items with names that were posted repeatedly using paper media, signal intensity was found to be heightened in the prefrontal cortex.

Findings obtained using neuromarketing methods indicate that these methods offer indispensable tools for the development of products and services that engage reward systems, or in other words, engage consumer desire.
\end{abstract}

Key words: neuromarketing, direct marketing, direct mail, NIRS, brain imaging, prefrontal cortex, reward system

\section{INTRODUCTION}

The results of an A/B test carried out by Company $\mathrm{C}$ and Company $\mathrm{P}$, two leading soft drink brands, revealed that although Company $\mathrm{P}$ won by a slim margin in blind taste tests, Company $\mathrm{C}$ received overwhelming support in taste tests where the brand logos were shown (Lindstrom, 2008). Moreover, although Hillary Clinton dominated in market surveys carried out before and after the 2016 United States Presidential Election, Donald Trump was, in fact, elected as the President (Brain Juicer Group, 2016). These examples, indicative of others, demonstrate that estimated data based on arbitrarily extracted samples, such as the results of interview studies and questionnaire surveys, will, depending on the sample size, statistically, occasionally result in major errors. Studies that are unable to

*TOPPAN FORMS CO., LTD. is a printing company that provides marketing services (particularly via direct mail). Taking advantage of neuromarketing, it is engaged in the development of various products and services. This paper introduces some of these initiatives.

We would like to express our deep thanks to Neuro-techniKa Co., Ltd. (Representative Director and President, Haruyoshi Hosono), who has always provided a high level of information and support as a marketing innovator. Without their cooperation, we would have been unable to realize the development of an empirical marketing method by utilizing brain imaging.

Correspondence concerning this article should be addressed to Toshiyuki Ochiai, LABOLIS Research Group, Marketing Department, Planning Division, TOPPAN FORMS Co., LTD., 1-7-3 Higashi Shinbashi, Minato-ku, Tokyo 105-8311, Japan (e-mail: ochiai-t@toppan-f.co.jp). 
secure an adequate sample size are without value (iStat, Inc., 2014; Oppenheimer, Meyvis, \& Davidenko, 2009).

The human decision-making process involves competition between logical top-down processing by the cerebral cortex (System 2) and emotional bottom-up processing by the limbic system (System 1, often derided as the "lizard brain"; Genco, Pohlmann, \& Steidl, 2013). The presentation of information using only text can easily lead to logical decisions and choices mediated by System 2; however, when textual information carrying the same content is supplemented with other modalities, such as images, videos, sounds, or scents, the resulting decision-making process will be influenced by System 1. The results obtained will thus vary significantly according to the method(s) used to present information. Human responses can therefore only be the result of this competition between Systems 1 and 2 in the brain (Ambler, Ioannides, \& Rose, 2000.).

Using brain imaging methods allows us to observe human brain activity in a noninvasive manner. Brain imaging offers a route to understand the processes of detection, recognition, and judgment — in other words, the human decision-making process - without having to wait to observe its behavioral consequences. It is well known that in interview studies and questionnaire surveys, consumers behave in ways they consider to be optimal (but which are at odds with reality). However, by using brain imaging, it is possible to identify the processes of detection, recognition, and judgment before observing the behavioral consequences. Furthermore, brain imaging also offers a bird's-eye view of the respective involvement of Systems 1 and 2 in the brain.

The process of incorporating brain imaging methods into marketing in an attempt to evaluate decision-making processes among complex individuals is known as neuromarketing. Firms already making active use of such methods, have begun to emerge overseas; however, this method of not asking people, who are subject to bias and tricky reactions, but rather asking the brain directly is yet to receive widespread recognition in Japan.

Toppan Forms Co., Ltd. perceives neuromarketing as a 21st century tool and are currently using it in the development of marketing using direct mail (DM). DM is a form of media made from paper and other materials that can be held in the hand and which is designed to stimulate all five senses. We believe DM to be an indispensable method for continuing to discover consumers' latent needs while responding to consumer-base diversification and consumer preference fluidity.

This study reports on part of our verification of the direct marketing process carried out using a technique that Toppan Forms has utilized in recent years, known as NIRS (nearinfrared spectroscopy), which is a system used to visualize brain function.

\section{Materials AND Methods}

Purpose

Using brain imaging, we evaluated the impact and appeal of original DM samples. This paper reports on our evaluation of the following four items:

(1) Comparison of paper media (target) with display media (control) on tablet-type devices;

(2) Comparison of a one-time presentation (target) versus multiple presentations (control); 
(3) Verification of the effect of bynames [on (target), off (control)]; and

(4) Verification regarding the number of items presented [condition A (target), condition B (control)].

Participants

A total of 31 subjects were employed in these studies. At the time of the experiment, all subjects were provided with written explanations. Brain function measurements were carried out only after obtaining written consent. Participants were remunerated with a payment of 6,000 JPY per session at the completion of the experiment. When the number of participants differed for each experiment, the actual numbers are indicated in the text.

\section{Procedures}

DM Content Used as a Stimulus We prepared 13 types of DM materials with text- and image-based information having the same level of sophistication as contents distributed in an actual DM that was printed on high-quality paper. In terms of the method of presentation, two methods were employed: (1) the contemplation condition, where participants were asked to look at the DM materials for at least 20 seconds, and (2) the free viewing condition, where participants were able to gaze at the materials freely.

We compared a target and control condition in each comparison/verification paradigm using the results of the summed value NIRS brain imaging. NIRS summed value brain imaging across subjects under stimulation and control conditions were obtained for the above four conditions.

Procedure for presenting DM materials was performed as follows: (1) baseline data were obtained for the period when the subject was gazing the target mark; (2) each DM material was presented under the free viewing condition or the contemplation condition; and (3) the subject was advanced to the next task after a taking a rest of a specified duration.

Equipment Used for Brain Function Measurement For the collection of brain imaging, we used a 48ch NIRS brain function imaging device employed in research (LABNIRS, manufactured by Shimazu Corp.) and observed sites where cerebral oxygen demand increases for challenges, known as NIRS high-signal regions (i.e., activation sites). It should also be noted that we set the sampling frequency for the NIRS brain function imaging to $6 \mathrm{~ms}$, and in block design, NIRS was measured for 15-20 seconds. A participant's Oxy-Hb signal when gazing at the black circle indicator ( 20 seconds) was taken as the baseline value in NIRS imaging.

\section{ReSUltS}

\section{Result (1): Comparison of paper media with display media on tablet-type devices}

Fig. 1 shows the summed value imaging of all subjects $(\mathrm{N}=6$ (4 females/2 males)), with results for participants viewing a transmitted light medium on the upper row and viewing paper media on the lower row.

When viewing paper media and when viewing display media on tablet-type devices, the signal intensity in the prefrontal cortex region was observed to have a relation such that [paper media $>$ display media on tablet-type devices]. For paper media, heightened signal intensity was also observed in the left temporal lobe. The brain reaction index also shows that signal intensity rises when looking at paper media (Fig. 2)

The summed value (Display color bar with zero median) NIRS imaging obtained from 6 subjects (4 females/2 males) is shown in Fig. 1. The NIRS imaging for subjects gazing at the paper is in the upper row; imaging for participants looking at the slate display is in the lower row. From left to right, the mapping view shows imaging from the occipital (visual) cortex, frontal (attention, vigilance, addictive) cortex, left temporal cortex, and right temporal cortex (auditory, linguistic).

The color bars on the right side of each NIRS imaging indicate the Oxy-Hb signal level. A higher Oxy-Hb signal level will be red in color. Imaging shows blue in certain 

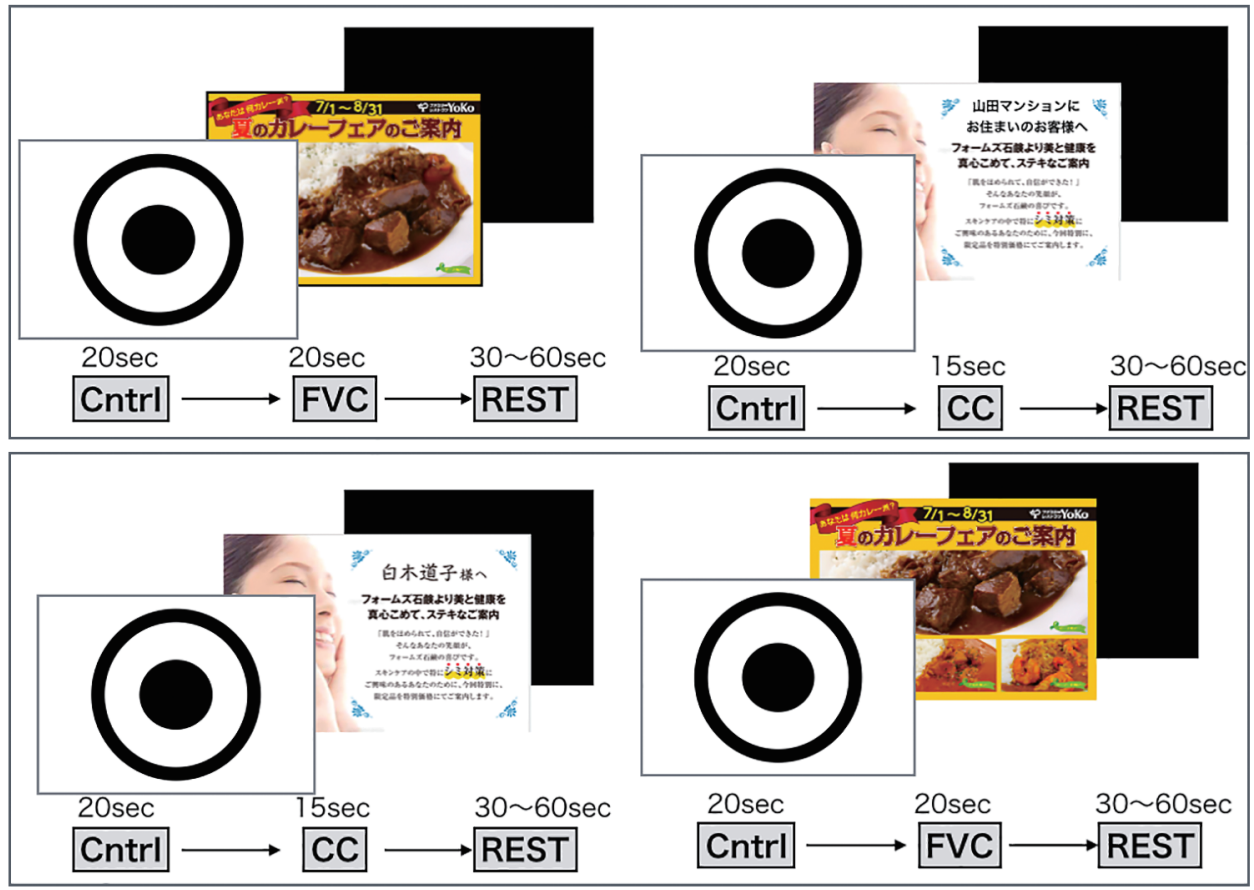

* $\mathrm{FVC}=$ free viewing condition, $\mathrm{CC}=$ contemplation condition

Fig. 1. Procedure for presenting DM materials

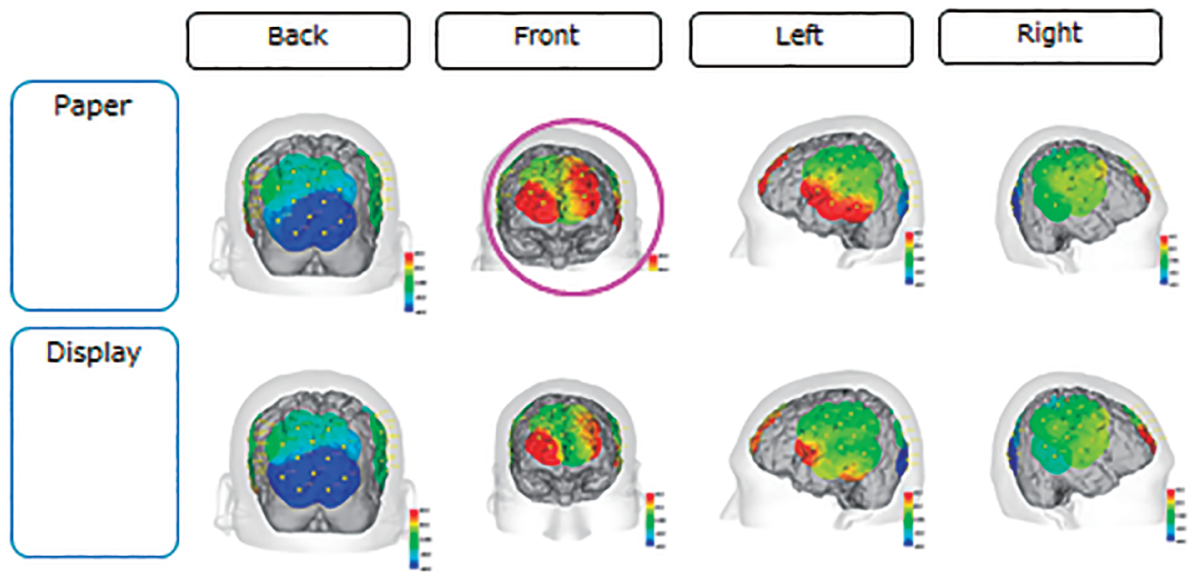

Fig. 2. Paper and Display Experiments

region indicates there is no change in the $\mathrm{Oxy}-\mathrm{Hb}$ signal level.

In the condition among Paper versus Slate display, NIRS imaging for the Paper option has a wider reaction area in the left prefrontal cortex than that found for the slate terminal display (iPad Air). 


\section{Reactions to Paper and Display as Seen in the Brain Reaction Index}

(Response Differential between Left and Right Temporal Cortex and Frontal Cortex When Occipital Cortex is Given a Measurement Value of Zero)

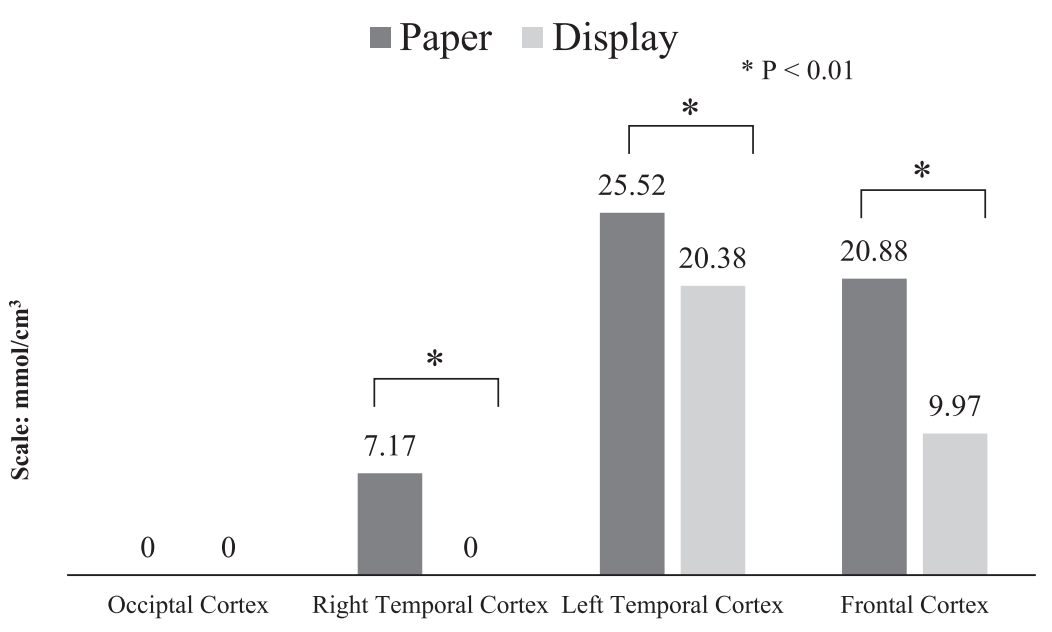

Fig. 3. Paper Media and Display Media and their Numerical Values

Regarding the frontal cortex (right: Fp 2.F 2.F 6. AF 6, left: Fp 1.F 1.F 5.AF 7) and occipital cortex $(\mathrm{O} 1 \cdot \mathrm{PO} 7 \cdot \mathrm{P} 1 \cdot \mathrm{P} 5$ and $\mathrm{C} 2 \cdot \mathrm{PO} 6 \cdot \mathrm{P} 2 \cdot \mathrm{P} 6)$, the Oxy-Hb signal total integral values were determined. We conducted a t-test on paper ( $\square$ paper) and slate displays ( display). A larger Oxy-Hb signal would be confirmed for the paper ( $\mathbf{\square}$ paper) condition under any condition of right frontal lobe, left frontal lobe, frontal lobe left/right summation $(p<0.01$, Wilcoxon signed-rank test). No increase in the Oxy-Hb signal was observed in the occipital lobe (O1, PO7, P1, P5 and C2, PO6, P2, P6).

Incidentally, the Brain Response Index is an indicator designed to convey the obtained event to people in the marketing field, who are not familiar with neuroscience in an easily understood form.

In addition, since the negative numerical value of occipital lobe of the subject was large, it has been displayed as zero. Since the numerical value of the display on the right temporal cortex was slightly negative, it has been expressed as a zero value, and its negative value was added to the paper media to indicate the difference with the paper media. The left temporal cortex and frontal lobe are expressed in real numbers as they are.

\section{Result (2): Comparison of a one-time presentation versus multiple presentations}

In the comparison of the impact of a one-time presentation versus multiple presentations ( $\mathrm{N}=6$ (4 females/2 males), we found that cases in which the same image was seen twice (upper row) yielded differences in signal intensity in the prefrontal cortex and left temporal cortex compared to cases in which different images were seen (lower row).

The pattern on the left side of the figure shows the image only once, whereas the 


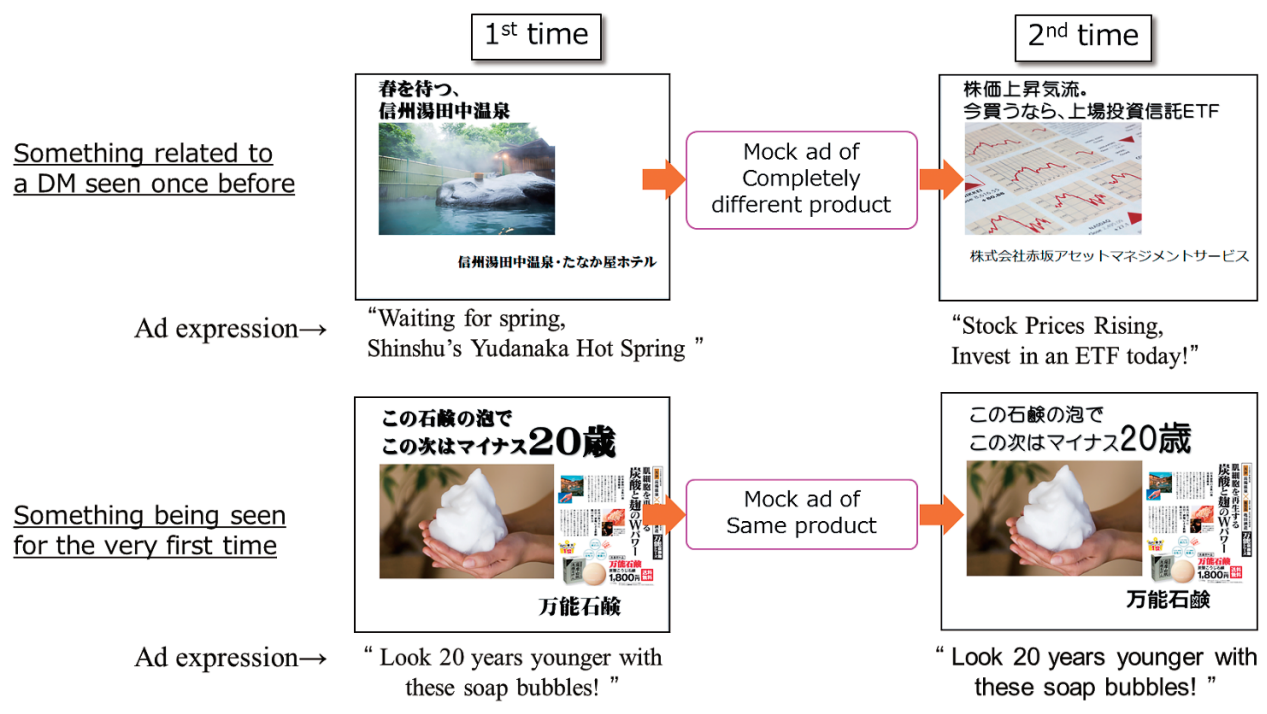

Fig. 4. Demonstration Pattern for "Is the Picture Different or the Same?"

example on the right side shows the same image repeatedly. We investigated the "appealing effect" induced by repetition.

NIRS image for repeated mock-advertisement image presentation and NIRS of single-time mock-advertisement image presentation

When comparing the NIRS images, the response in the left temporal cortex can be observed in both ( $\mathrm{N}=\mathrm{XX}$, the summed value image is shown.)

\section{Result (3): Verification of the effect of bynames}

A comparative study was conducted by presenting participants with personalized brochures containing their names versus impersonal ones without specific names $(\mathrm{N}=12$ ( 7 females $/ 5$ males). The results revealed that signal intensity was observed to rise in the left prefrontal cortex for personalized brochures more than for impersonal ones.

When a participant's own name was included, the Oxy-Hb signal in the left prefrontal cortex increased. It is considered to be a useful approach for expressing attention even simply by writing a byname ( $\mathrm{N}=\mathrm{XX}$, the summed value image is shown).

\section{Result (4): Verification regarding number of items presented}

The impact of number of items presented was assessed using two different presentation layouts (i.e., a flyer and DM) for cases involving a large number of product items versus cases in which only a few items were presented $(\mathrm{N}=13,7$ females $/ 6$ males).

Signal intensity in the prefrontal cortex increased when subjects were presented fewer items, regardless of layout.

Both types of flyer layouts and DM layouts were applied for the verification regarding the number of items presented paradigm. The right temporal view (right) of the image, the 

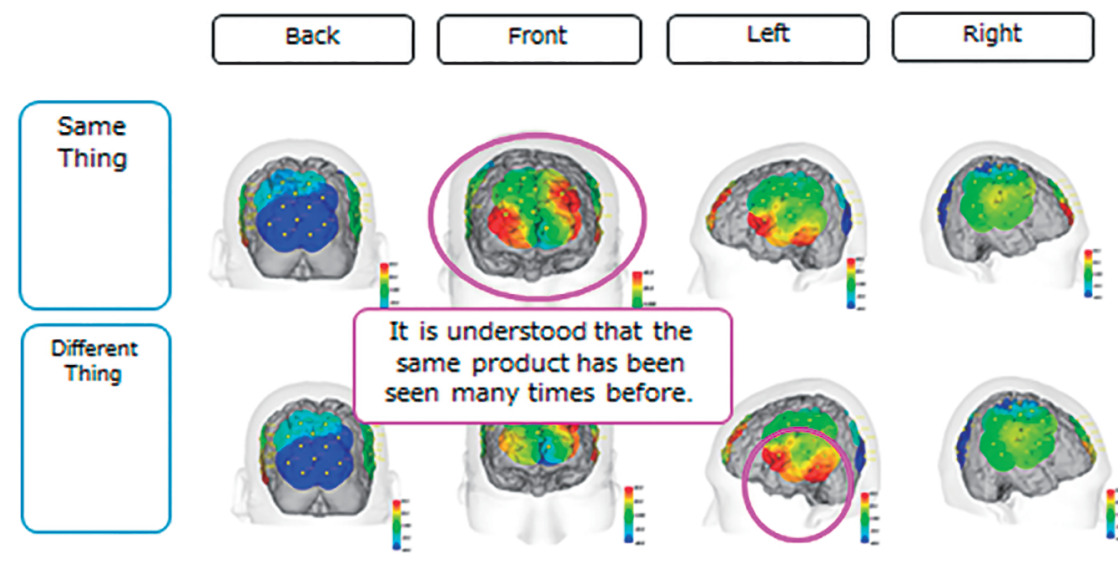

erstood that the ame product has been
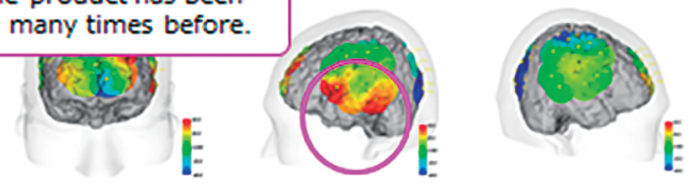

\section{Attempting to interpret something being seen for the first time.}

Fig. 5. NIRS imaging for "Is the Picture Different or the Same?"

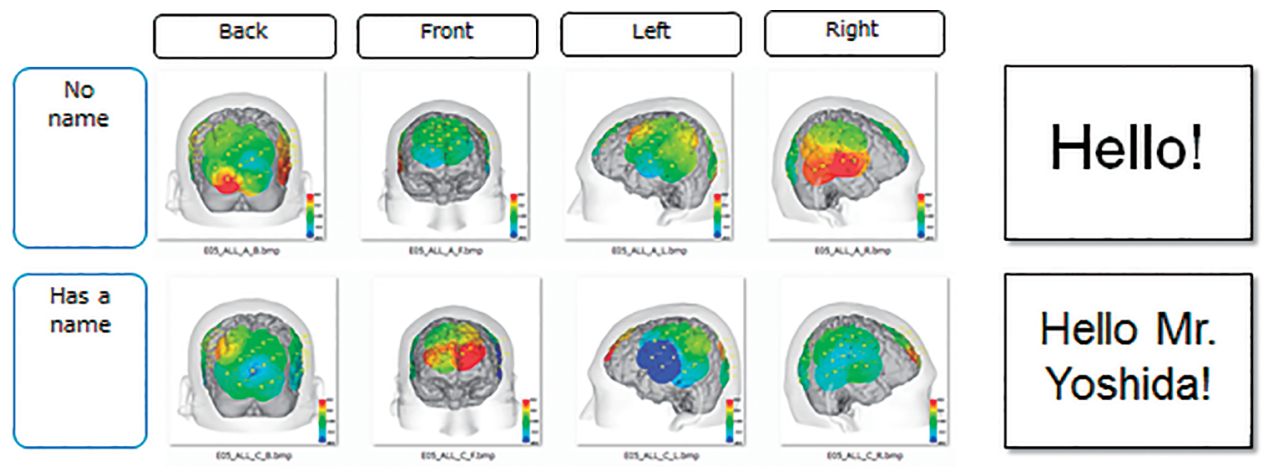

Fig. 6. NIRS image results for "Verification of the effect of bynames."

left temporal image (left), the frontal image (front), and occipital image (back) are shown, respectively, from the left. It is found that the intensity of the Oxy-Hb signal in the prefrontal cortex is stronger when the highlighted image was presented (upper row) than in the other cases (lower row). In the case of the flyer layout, the Oxy-Hb signal in the prefrontal cortex is very weak when many presentation items are present.

\section{Interpretation of Results}

The prefrontal cortex is the site of the brain that shows reactions by the reward system. Therefore, increased signal intensity in this region, measured here using NIRS signal intensity, signifies that interest is high. High signal intensity in the medial orbit is considered to indicate that although interest is the same, it is also accompanied by impulsivity [3]. 
The left and right temporal cortexes are sites where reactions arise, respectively, when processing information in chronological order. Signal intensity is considered to increase in the left temporal cortex when performing logical processing, such as when understanding textual information, and in the right temporal cortex when processing information in sensory areas, such as that involving figures and colors.

Based on this brain-mapping paradigm, our interpretations were made according to the observed differences in NIRS signal intensity between the prefrontal and temporal cortices with regard to these four items.

\section{Paper Media and Tablet-Type Display Media}

With increased use of smartphones and tablet devices, the distribution of information not only on paper media but also as full-color information similar to the DM through the Internet and e-mail has become more frequent. Because the luminosity of information presented on paper media as seen in reflected light differs from that of display media seen through transmitted light, even if the same information were to be presented, it is conceivable that different effects will occur at the psychological or attentive levels. In this study, we compared cases of paper media viewed under identical degrees of luminosity and in conditions where the brightness of the display media was adjusted so as not to cause glare.

Signal intensity was observed to increase in the prefrontal and left temporal cortices in the paper media group. This suggests that the natural luminosity of paper media made it easier to secure and maintain readability and interest to a greater degree than in the display media.

\section{Comparison of One-Time Presentation versus Multiple Presentations}

In the experiments assessing one-time and multiple presentations, signal intensity was observed to increase in the prefrontal and left temporal cortices in the context of multiple presentations. Information conveying a sense of déja $v u$ was more likely to elicit attention than information that did not. It seems highly probable that this was perceived as the appearance of a reaction of the same character as P300, which occurs in attention tasks using so-called event-related potential or oddball tasks.

\section{Verification of the Effect of Bynames}

We examined whether the presence or absence of bynames had any effect on the retention of viewing attention. From the fact that signal intensity was observed to increase in the left prefrontal cortex when participants' own names were printed in a brochure, it appeared that, depending on the name, interest in the logical information would be further heightened and that the reading of the text could be anticipated.

\section{Verification Regarding Number of Items Presented}

Regardless of the layout chosen (flyer or DM), fewer presented products resulted in higher signal intensity in the prefrontal cortex. In other words, it was confirmed that interest was heightened further when fewer products were depicted. 


\section{Discussion}

\section{Defining “Good” DM}

Good DM refers to that which correctly conveys to target viewers certain information or messages and which simultaneously imprints the relevant brands and product names, ultimately triggering desire that leads to a purchasing action. However, this is not to say that an archetype for good DM exists; rather, it is necessary to customize materials according to the information and messages one wants to convey (Simpson, 2016).

Fig. 7 reports on the four items of Paper and Display (\#11), Multiple Item Contacts (\#12), Response When Names are Listed (\#25), and Zoning (\#32). In fact, we have also verified items other than these using brain imaging. By doing so, we are gradually accumulating the knowledge necessary for gradually creating better DM.

Fig. 8 offers a diagram showing the relationship between the main four vectors and each of the components that needs to be considered when creating direct mail. The vertical axis contains issues relevant to both DM and general marketing; the horizontal axis shows the relationship between tactical and strategic tasks. The themes studied this time correspond to \# 2a, \# 21 \# 23, \# 24, \# 25, \# 26, and \# 28.

\section{Purpose of Utilizing Brain Imaging}

When a sample of sufficient size can be secured from the normalized population, the information obtained from studies on that sample will therefore be sufficiently reliable in statistical terms. In terms of mass marketing that targets large groups of an unspecified number, this perspective enables the results of interview and questionnaire surveys to be considered reliable. However, as globalization progresses, societies are increasingly heterogeneous, and consumer behavior and preferences have diversified considerably. The movements of people and goods have grown increasingly dynamic, and as information is also being transmitted and shared over the Internet, society is finally becoming borderless. Arguably, the groups of normalized consumers posited by mass marketing no longer exist anywhere.

What kind of marketing is best for reaching consumers in such a fluid and heterogeneous period? A number of new recommendations have already been proposed. Examples of these are the creation of an Internet of Things (IoT) and analyzes that draw on Big Data. Such mass-marketing methods, however, are not well-suited to ascertaining niche markets or potential consumer needs. Furthermore, IoT does not produce data without the diffusion of products, while Big Data, similarly, is nothing more than aggregate consumer behavior. Therefore, it is difficult to predict the future based on such results. Forecasting outcomes when introducing innovative products and novel services to the market will require new concepts and approaches that are able to abandon old ways of thinking (Ariely \& Berns. 2010; Smidts et al., 2014).

We believe that one such answer is neuromarketing carried out using brain imaging. We have accumulated a substantial body of knowledge regarding a sizable number of DM methods by utilizing neuromarketing evaluation methods. Such knowledge potentially transcends the experience value of qualified marketing personnel, results of market surveys 


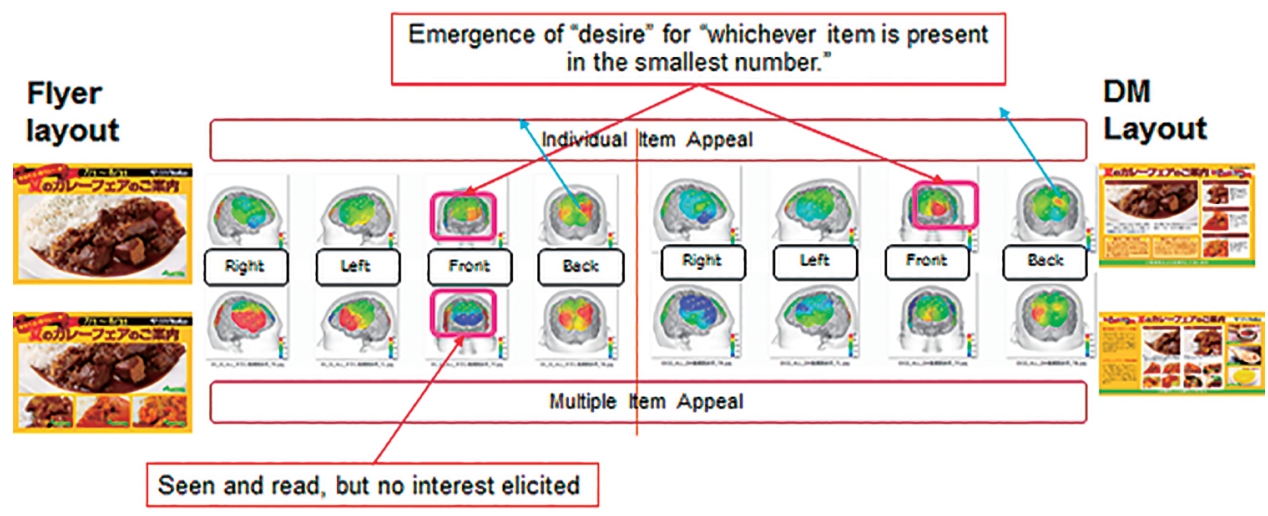

Fig. 7. Demonstration Pattern for verification regarding the number of items presented and these NIRS images results.

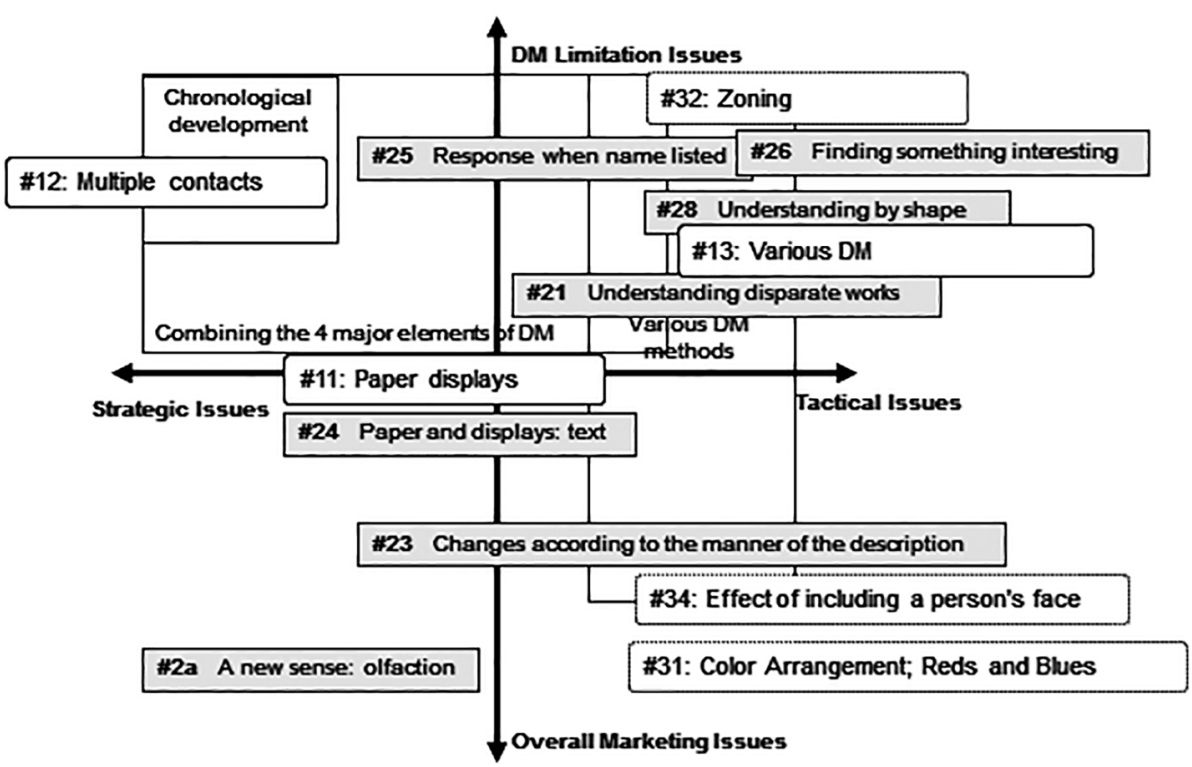

Fig. 8. Points to be discussed in the context of DM creation (Marketing Challenges and Experiment Overlay)

such as interviews and questionnaires, and results of direct-marketing tests. Furthermore, this experience has also led to successful development of completely novel DM service methods (TOPPAN FORMS CO., LTD., 2015a, 2015b). We believe that neuromarketing is a marketing innovation for this century.

There are two ways to apply neurophysiological techniques to marketing.

One is a method of statistical evaluations to know trends, similar to the Big Data method. 


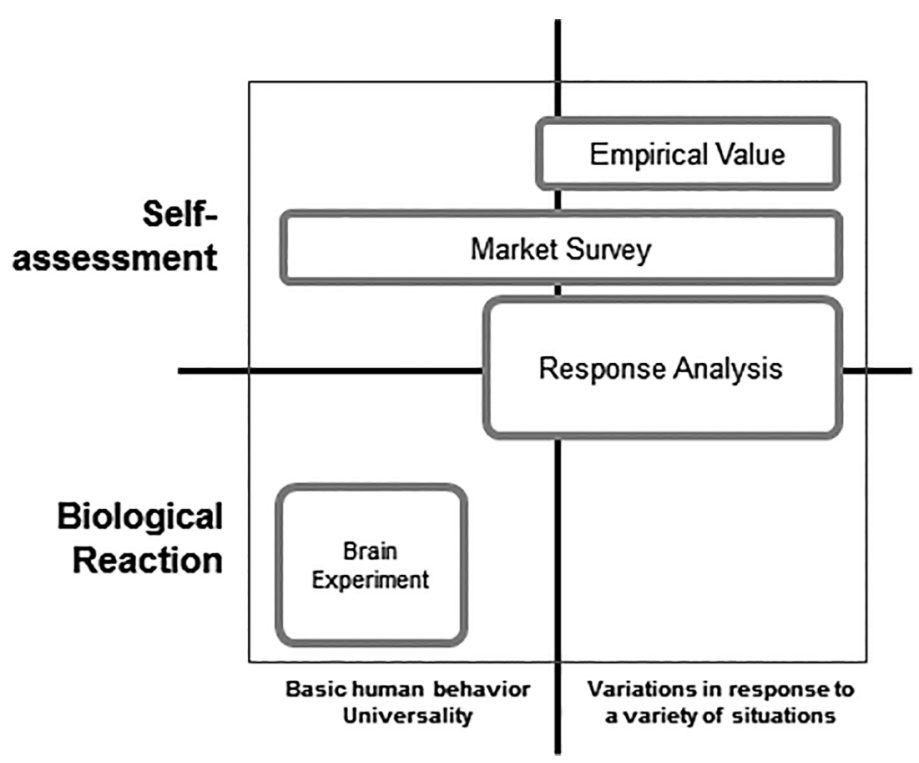

Fig. 9. Survey Methods

The other method is to establish a focus group (client group with distinct taste) and this learn behavior trends of this limited consumer pool. This study was performed based on subjects corresponding to TOPPAN FORMS CO., LTD (TF's) special target customer as the focus group. In a sense, it can be regarded as a population study with bias. For that reason, we could not construct statistical tests. Furthermore, corporate confidentiality prevents us from providing details on the focus group. To address this limitation, we intent to next add statistical thinking comparable to Big Bata analysis to the neuromarketing method.

\section{CONCLUSION}

Toppan Forms Co., Ltd., as a B2B business firm, consults on information transmission and proposes more effective direct marketing and better DM creation for our clients from both the industry and public sectors. The use of neuromarketing that utilizes brain imaging offers a novel and highly promising route to substantially improving the appeal of DM and $\mathrm{t}$ quality of information transmission brought about by such initiatives.

This paper aimed to convey the significance of our efforts and the usefulness of neuromarketing. 


\section{REFERENCES}

Ambler, T., Ioannides, A., \& Rose, S. 2000. Brands on the brain: Neuro-images of advertising. Business Strategy Review, 11(3), 17-30.

Ariely, D., \& Berns, G. S. 2010. Neuromarketing: The hope and hype of neuroimaging in business. Nature Reviews Neuroscience, 11, 284-292.

Brain Juicer Group. 2016. Brian Juicer Blog. A blog by BrainJuicer about turning human understanding into business advantage. Edited by Tom Ewing. Retrieved from https://www.system 1 research.com/blog/ 5-questions-to-make-your-digital-content-better

Genco, S., Pohlmann, A., \& Steidl, P. 2013. Ten scientific pillars underlying neuromarketing. In S. Genco, A. Pohlmann, \& P. Steidl (Eds.), Neuromarketing for dummies (pp. 371-378). Hoboken, NJ: John Wiley \& Sons. Retrieved from http://intuitiveconsumer.com/blog/science-under-the-hood-1-system-1-andsystem-2-priming

iStat, Inc. 2014. Mix skill up series: MR muke toukei nyumon: Dai 2/3 kai text [Mix skill up series: Introductory statistics for marketing researcher: 2nd and 3rd text]. Retrieved from http://istat.co.jp/files/19fdcbe987 1d2c0dde10cf5b41bb31d0.pdf

Lindstrom, M. 2008. Buyology. New York, NY: Crown Business.

Oppenheimer, D. M., Meyvis, T., \& Davidenko, N. 2009. Instructional manipulation checks: Detecting satisficing to increase statistical power. Journal of Experimental Social Psychology, 45, 867-872.

Simpson, C. 2016. The advertising solution. Irvine, CA: Entrepreneur Press.

Smidts, A., Hsu, M., Sanfey, A. G., Boksem, M. A. S., Ebstein, R. B., Huettel, S. A., . . . Yoon, C. 2014 Advancing consumer neuroscience. Marketing Letters, 25, 257-267. doi: 10.1007/s11002-014-9306-1

TOPPAN FORMS CO., LTD. 2015a. Toppan Forms wins awards in two categories, USPS Gold Mailbox and Silver Awards, at the 2015 DMA International ECHO Award. Retrieved from http://labolis.toppan-f. co.jp/en/topics/284/

TOPPAN FORMS CO., LTD. 2015b. Introduction of "Anything for The Receiver's Smile" that is B to B Direct Mail campaign. Retrieved from https://www.youtube.com/watch?v=MjlM7TqG9lw

(Manuscript received 29 November, 2016; Revision accepted 15 March, 2017) 